\title{
FUNCIONALIDAD DEL TERRITORIO DE LAS COMUNIDADES AUTONOMAS
}

\author{
$71: 353.072 .1$
}

por

José-Luis Meilán Gil

Catedrático de Derecho Administrativo de la Universidad de Santiago de Compostela

SUMARIO: I. INTRODUCCION.-II. EL SENTIDO DE LA RELACION TERRITORIO-COMUNIDAD AUTONOMA.-III. DEFINICION DEL TERRITORIO DE LA COMUNIDAD AUTONOMA.IV. FUNCIONALIDAD DEL TERRITORIO: 1. DELIMITACIÓN DE COMPETENCIAS. 2. La ORGANIZACIÓN JUDICIAL. 3. DERECHOS INDIVIDUALES. 4. LA ORDENACIÓN DE LAS ADMINISTRACIONES PÚBLICAS.

\section{INTRODUCCION}

Las Comunidades Autónomas constituyen una de las más importantes - y preocupantes - innovaciones de la Constitución Española de 1978. La afirmación es tópica y no necesita refrendo bibliográfico alguno. Superado el período constituyente con la aprobación de la Constitución en el sentido técnico-constitucional, durante bastante tiempo ese carácter constituyente dominará el trabajo de los investigadores del Derecho público español, que no podrá en muchas ocasiones dejar de sufrir los efectos de la inestabilidad del desarrollo constitucional al traducir la legislación positiva los pro- 
pios vaivenes del acontecer político y las sucesivas «lecturas» de la Constitución (1).

En gran medida esa circunstancia deriva del carácter deliberadamente, o si se prefiere objetivamente, abierto de la Constitución en esta materia (2). Pese a la ya abundante bibliografía existente y de la importante aportación del Tribunal Constitucional, no pocas cuestiones centrales siguen todavía en pie, y las relaciones cotidianas entre las Comunidades Autónomas y el Estado se presentan cargadas de tensiones que no reflejan movimientos tácticos, propios del pluralismo democrático y de instancias diferentes del Poder, sino que responden a la ausencia de reglas claras o de experiencia jurisprudencial acumulada que pudiera evitarlas o disminuirlas.

Por ello, cualquier punto del ordenamiento comunitario puede resultar doblemente conflictivo: tanto por los problemas que en sí mismo doctrinalmente entrañe, como por la concepción global del fenómeno autonómico desde que se analice.

El presente trabajo está realizado desde la óptica de una realidad concreta, la del Estatuto de Autonomía de Galicia. Resulta innegable, sin embargo, que una serie de aspectos del mismo son comunes con las demás Comunidades Autónomas. Al hilo, por tanto, del examen del caso gallego se realiza una primera aproximación al problema del territorio de las Comunidades Autónomas.

(1) Las fluctuaciones de que se habla en el texto se observan ya en el período de elaboración del proyecto constitucional. Basta comparar el borrador publicado el 25 de noviembre de 1977 con el anteproyecto $(B O E, 5$ enero 1978) y el texto definitivamente aprobado de la Constitución $(B O E, 29$ diciembre 1978). Y continúan después: posiciones ante el Estatuto gallego; referéndum andaluz; debates en torno a la moción de censura y cuestión de confianza del Gobierno Suárez en 1980; Pactos autonómicos Gobierno UCD-PSOE de 31 de julio de 1981. Sobre el tema puede consultarse "Informe de la Comisión de Expertos sobre autonomías», de 19 de mayo de 1981, presidida por E. Garcfa de ENTERRía; S. MuÑoz MACHADO: Derecho público de las Comunidades Autónomas, I, 1982, cap. III; J. L. MEILÁN GiL: El Estatuto gallego, 1980; Clavero ArÉvalo: España, desde el centralismo a las autonomias, 1983; E. AtTaRd: La Constitución por dentro, Madrid, 1983; J. Leguina Villa: «El porvenir de las autonomías», en Escritos sobre autonomías territoriales, 1984; S. MuÑoz MACHADO: "La interpretación de la Constitución, la armonización legislativa y otras cuestiones», en $R E D C, 9$ (1983).

(2) G. ARIÑo ORTIZ: «El Estado de las autonomías: Realidad política, interpretación jurídica», en La España de las autonomías, Espasa-Calpe, Madrid, 1981, tomo II, págs. 14 y ss. y bibliografía allí citada; L. LOPEZ RoDó: En torno a la indefinición constitucional del modelo de Estado, Real Academia de Legislación y Jurisprudencia, Madrid, 1984; MuÑoz MaCHADO, op. cit., págs. 153 y ss. y bibliografía citada; J. L. MeILÁN GIL: «El marco jurídico de las autonomías», en Autonomía, Hacienda y Régimen local de Galicia, Universidad de Santiago de Compostela, 1981. 


\section{EL SENTIDO DE LA RELACION TERRITORIO- COMUNIDAD AUTONOMA}

El artículo 147, 2, b), de la Constitución Española (en adelante $\mathrm{CE}$ ) señala como un elemento necesario de los Estatutos de Autonomía ("deberán contener») «la delimitación de su territorio», que ha de entenderse referida - aunque no muy propiamente desde el punto de vista gramatical - a la Comunidad Autónoma, citada en el apartado a).

El sentido de la relación del territorio con la Comunidad Autónoma implica una toma de posición respecto a la naturaleza de éste. Hasta la Constitución de 1978, los problemas del territorio se desenvolvían en el marco de la relación Estado-Entidades locales, que correspondía a una estructura estatal centralizada, en la que el principio organizativo de la tutela operaba con naturalidad (3).

La aparición de las Comunidades Autónomas obliga a su diferenciación respecto de las Entidades locales y del Estado, en una de las acepciones que tanto la Constitución como el Tribunal Constitucional emplean precisamente para aquella finalidad (4). Según la concepción metajurídica que explícita o implícitamente se adopte, las respuestas jurídicas a las cuestiones que plantee el territorio estarán más cercanas del ámbito local o del estatal. La existencia de nacionalismos organizados políticamente hace que esa alternativa no sea puramente hipotética, como reflejan los casos sobre los que han recaído las sentencias del Tribunal Constitucional (5).

La novedad del fenómeno no impide la utilización, con cierta cautela, sin embargo, de las reflexiones doctrinales realizadas sobre la territorialidad de los Entes locales, como tampoco fue ajena la doctrina administrativa a las aportaciones de internacionalistas y constitucionalistas respecto del territorio del Estado (6).

(3) Cfr. S. Royo-Villanova: Los términos municipales y sus alteraciones, Madrid, 1947; F. GARRIDO FALLA: Administración indirecta del Estado y descentralización funcional, Madrid, 1950; A. GuaITA: División territorial y descentralización, Madrid, 1975.

(4) Cfr. sentencia del Tribunal Constitucional de 28 de julio de 1981.

(5) Por citar unos ejemplos significativos, cfr. sentencia del Tribunal Constitucional de 28 de julio de 1981 sobre la Ley 6/1980 del Parlamento catalán, de transferencia urgente y plena de las Diputaciones catalanas a la Generalidad; o sentencias del Tribunal Constitucional 85/1983, de 25 de octubre, y 171/1983, de 29 de noviembre, sobre conflictos de competencias relativos al ingreso en la función pública local en el País Vasco y sobre Notarías en Cataluña, amén de numerosos conflictos en materia de transportes, energía, cooperativas, etc., que se examinarán más adelante.

(6) Cfr. A. NiETo: «Entes territoriales y no territoriales», en $R A P, 64$ (1971), páginas 29 y ss.; M. DfAz DE VELASCO: Instituciones de Derecho internacional pú- 
El estudio del territorio de las Comunidades Autónomas ha de partir, al menos, de dos premisas: a) «El Estado se organiza territorialmente en Municipios, en Provincias y en las Comunidades Autónomas que se constituyan» (art. 137 de la CE). b) Autonomía política de las Comunidades Autónomas.

El Tribunal Constitucional ha tenido ocasión de precisar esas ideas:

«La Constitución prefigura, como antes deciamos, una distribución vertical del poder público entre entidades de distinto nivel que son fundamentalmente el Estado, titular de la soberanía; las Comunidades Autónomas, caracterizadas por su autonomía política, y las Provincias y Municipios, dotadas de autonomía administrativa de distinto ámbito» (Sentencia del Tribunal Constitucional de 28 de julio de 1981; en el mismo sentido, sentencia del Tribunal Constitucional de 2 de febrero de 1981).

La superior cualidad de la autonomía de las Comunidades Autónomas queda patente, "ya que se añaden potestades legislativas y gubernamentales» (sentencia del Tribunal Constitucional de 14 de julio de 1981), aunque se las incluye conjuntamente con Provincias y Municipios en la expresión "Entidades territoriales». Si bien se concreta en la misma sentencia que aquéllas son "Corporaciones públicas de base territorial y de naturaleza política», que «tienen como esfera y límite de su actividad, en cuanto tales, los intereses que les son propios, mientras que la tutela de los intereses públicos generales compete por definición a los órganos estatales».

Las conclusiones de un sector de la doctrina sobre la noción de Ente territorial (7) pueden repristinarse con ocasión de las Comunidades Autónomas. La territorialidad «como consecuencia de la naturaleza política que tienen ciertos Entes» (ALESSI) adquiere aquí completa relevancia, liberada de las prudentes limitaciones que desde ese punto de vista afectan a los Entes locales, y, por supuesto, «sirve para determinar la esfera de acción de la actividad total del Ente» (NIETo) en una misión instrumental clara, aunque no despreciable.

La conexión entre el territorio y los fines del Ente constituyen, sin duda, una buena dirección (8). El diferente alcance de la «auto-

blico, 1, 5." ed., 1980, págs. 261 y ss.; N. Pérez Serrano: Tratado de Derecho político, 2." ed., 1984, págs. 97 y ss. y bibliografía citada en ellos. M. HERRERo R. DE MiÑón: "La configuración del territorio nacional en la doctrina reciente del Consejo de Estado", en Libro jubilar del Consejo de Estado, Madrid, 1972, págs. 355-427.

(7) A. NiETo, op. cit., págs. 40-41.

(8) A. Nieto, op. cit., pág. 42. 
nomía para la gestión de sus respectivos intereses» referido a Municipios y Provincias, de un lado, y a Comunidades Autónomas, de otro, proporcionará un elemento clave para perfilar el alcance de la relación territorio-Comunidad Autónoma. No se trata, por supuesto, de incidir en la cuestión de la distinción de universalidad o concreción de fines utilizada para distinguir entre Entes territoriales y no territoriales (9), que de rechazo homogeneizaría a Comunidades Autónomas y Entes locales, sino de insistir en una nota esencial que caracteriza a las Comunidades Autónomas: la existencia de auténticas competencias exclusivas. El juego de estas competencias, en virtud de lo que dispone el artículo 149, 3, de la Constitución, conduce a la prevalencia o aplicabilidad preferente de las normas de la Comunidad Autónoma respecto de las del Estado. Aquí reside el meollo de todos los problemas de la autonomía política, en lo que coinciden los defensores de posturas contrapuestas (10).

Siendo las Comunidades Autónomas parte de la organización territorial del Estado es evidente que se produce una superposición física de territorios: el de la Comunidad Autónoma lo es al mismo tiempo del Estado. El problema, obviamente, no se plantea en términos físicos, sino jurídicos: hasta qué punto se puede dar una «impenetrabilidad vertical» del Estado en el territorio de la Comunidad Autónoma. Desde luego, la afirmación absoluta de contrario ("penetración o superposición de carácter total y sin ninguna excepción»), como se ha afirmado para los Entes locales respecto del Estado (11), habría de revisarse a la vista de la existencia y funcionalidad genuina de las competencias exclusivas, pese a los intentos

(9) Op. cit., págs. 38-39 y bibliografía allí citada; A. de LAUBADÈRE: «Vicissitudes actuelles d'une distinction classique: Etablissement public et collectivité territoriale», en Pages de Doctrine, París, 1980. La doctrina común se reproduce en la sentencia del Tribunal Supremo de 8 de julio de 1983 (Ar. 3986), en donde se recogen todas las notas: poderes jurídicos sobre la totalidad de la población, universalidad de fines; mayor amplitud de potestades administrativas, numerus clausus de las personas jurídico-públicas territoriales entre las que se colocan a las Comunidades Autónomas.

(10) Cfr. «Informe de la Comisión de Expertos...», cit.; E. García de EnTERrfa: «El ordenamiento estatal y los ordenamientos autonómicos», cap. VI del Curso de Derecho administrativo, en colaboración con T. R. FERNÁNDEz, tomo I, 4: ed., Madrid, 1983, y trabajos allí citados; L. PAREJo: La prevalencia del Derecho estatal sa bre el regional, Madrid, 1981. En distinta dirección, I. de OrTo: «La prevalencia del Derecho estatal sobre el Derecho regional», en REDC, 2 (1981). Las posturas se han bipolarizado en torno a la LOAPA: S. MuÑ̃z MACHADo, op. cit. en nota 1; L. Parejo ALFONSo: "Algunas reflexiones sobre la sentencia del Tribunal Constitucional de 5 de agosto de 1983 relativa al proyecto de ley orgánica del proceso autonómico», en $R E D C$, 9 (1983), págs. 117 y ss. En sentido crítico, G. Trujillo y otros: LOAPA y Constizución, Ed. Gobierno Vasco, 1982; J. Leguina Villa: Escritos..., cit., págs. 105 y ss.

(11) NiETo, op. cit., pág. 43. 
por destruirlas o negarlas, de los que la LOAPA y sus fundamentos doctrinales constituyeron el paradigma (12).

Desde luego, el sistema previsto en la Constitución no permite pronunciamientos radicales sobre la materia: de ahí que la prevalencia corresponderá al Derecho del Estado «en todo lo que no esté atribuido a la exclusiva competencia de éstos» (art. 149, 3, CE), y por la vía de la supletoriedad, puede aplicarse el Derecho del Estado en el territorio de la Comunidad (13); obviamente, tal aplicabilidad no ofrece dudas en el caso de competencias concurrentes o de las compartidas.

El territorio de la Comunidad Autónoma no puede desligarse de los intereses cuya gestión genéricamente les reconoce el artículo 137 de la Constitución. Pero esa gestión implicará en determinadas materias la titularidad y el ejercicio de la potestad legislativa. En ese sentido, la Comunidad opera como el Estado, viene a sustituir el funcionamiento del Estado anterior a la Constitución de 1978 y precisamente por una concreta previsión constitucional. La decisión constituyente consistió en atribuir a las Comunidades Autónomas la posibilidad de gestionar, desde su regulación legislativa, asuntos de interés general. Posibilidad que se concretó en los Estatutos, de acuerdo con la función que a éstos atribuye la propia Constitución, integrándose en el denominado «bloque de la constitucionalidad» (14), para lo que se ha dotado de los correspondientes poderes. Con acierto se ha afirmado que «el interés general no es un

(12) Cfr. «Informe...», cit.; E. GaRcf́a dE ENTERRfA: «Estudio preliminar» al volumen La distribución de competencias económicas entre el Poder central y las autonomias territoriales en el Derecho comparado y en la Constitución española, Madrid, 1980; «La significación de las competencias exclusivas del Estado en el sistema autonómico", en REDC, 5 (1982); S. MuÑoz Machado: Derecho público..., cit., I, páginas 357 y ss.

(13) Garcf́a de EnTERría ha extraído de esa cláusula general de suplencia «la prohibición de que un ordenamiento autonómico pueda intentar integrarse, completarse o suplir sus insuficiencias haciendo apelación a otro Derecho autonómico» (Curso..., cit., pág. 346), lo cual es dogmáticamente correcto.

A los efectos de que se trata en el texto, en conexión con el territorio, la vía de acuerdos o convenios entre Comunidades Autónomas, al amparo del artículo 145, 2, de la Constitución Española y de los respectivos Estatutos, permite la existencia de convenios con contenido normativo, que aunque no supongan la ampliación territorial en la competencia autonómica, ya que la norma vigente será la que proceda del respectivo órgano de la Comunidad Autónoma, sí pueden evitar la aplicación del Derecho del Estado sobre unas materias en las que las Comunidades tienen competencia exclusiva ("gestión de servicios propios» sin más, EA, art. 72; o además «de la exclusiva competencia» de la C. A.; art. 22 del EV; art. 27 del EC; art. 35 del EG). Sobre el tema vid. A. MENENDEZ ReXACH: Los convenios entre Comunidades Autónomas, 1982, que sigue la orientación doctrinal de A. Gallego ANABITARTe.

(14) Sentencia del Tribunal Constitucional 38/1983, de 20 de mayo; sentencia del Tribunal Constitucional 72/1983, de 29 de julio. 
título que pueda amparar la reserva de poderes genéricos e indeterminados en manos del Estado" (15).

Por ello, el criterio del interés de la Comunidad Autónoma, como contrapunto al interés general, ha de entenderse matizadamente, sin que puedan concebirse como reductos incomunicables, siempre alternativos. De ahí que el propio Tribunal Constitucional haya confesado en su primera sentencia:

«Concretar este interés en relación a cada materia no es fácil y, en ocasiones, sólo puede llegarse a distribuir la competencia sobre la misma en función del interés predominante, pero sin que ello signifique un interés exclusivo que justifique una competencia exclusiva en el orden decisorio» (Sentencia del Tribunal Constitucional de 2 de febrero de 1981).

La asignación de poderes al Estado y a la Comunidad Autónoma realizada desde el mismo nivel constitucional obliga a aproximar el planteamiento del territorio referido a la Comunidad al correspondiente del Estado. Desde esa perspectiva puede entenderse la eficacia de los poderes de la Comunidad Autónoma fuera de su territorio para la realización del interés comunitario que se estima predominante, o que los intereses supracomunitarios no se identifiquen necesariamente como intereses, cuya gestión deba ser competencia de los poderes del Estado (16).

El territorio, como se verá más abajo, desempeña un importantísimo papel para la determinación de la competencia -estatal o autonómica- $\mathrm{y}$, por tanto, es un problema central del Derecho: la elección de la norma aplicable a cada supuesto de hecho concreto.

Precisamente esa doble circunstancia -eficacia extraterritorial y determinación de la competencia - ayuda a esclarecer el significado del territorio de una Comunidad Autónoma. En la línea de la sugestiva hipótesis del profesor NIETo (17), habría que afirmar el carácter prioritario que tiene la Comunidad Autónoma por relación a la cual se delimita un territorio y se reconocen unos fines, la gestión de unos intereses propios. La emergencia positiva de las Comunidades Autónomas no siempre puede entenderse como un

(15) S. Muñoz Machado: Derecho público de las Comunidades Autónomas, I, Madrid, 1982, pág. 205.

(16) Pueden desarrollarse mediante la cooperación de varias Comunidades Autónomas. Cfr. MuÑoz MACHADO, op. cit., pág. 204 y bibliografía allí citada.

(17) Op. cit., págs. 43 y ss. La idea de Comunidad supone una apreciación más articulada que la de "conjunto de personas vinculadas a un territorio» de GaRRIDo Falla (Tratado de Derecho administrativo, vol. I, 8." ed., Madrid, 1982, pág. 366). 
fenómeno de carácter organizativo, que se inscribiría en un proceso de racionalización del Poder y de su ejercicio. La propia Constitución, al aludir en su artículo 2 al debatido concepto de "nacionalidades", o al hacer referencias a la historia (arts. 143 y 147, 2; disposición adicional primera; disposición transitoria segunda), está reconociendo la existencia de unas Comunidades a las que se les proporciona un ordenamiento jurídico (18).

Desde esa perspectiva, la delimitación del territorio correspondiente a esas Comunidades históricas no es caprichosa y no puede ser el fruto del voluntarismo del legislador. El papel que se suele asignar al territorio de los Entes locales - determinación del grupo que integra la Comunidad y actividades del Ente- (19) ha de ser, por tanto, necesariamente más amplio, situándose en la órbita del que desempeña en relación con el Estado. Evidentemente, subsisten diferencias notorias que pueden explicarse desde la óptica del Derecho internacional. Quizá la mejor manera de entender la funcionalidad de aquél sea su consideración desde la concepción estatutaria del Derecho intermedio, más aún que desde la del Estado federal (20). En definitiva, las Comunidades Autónomas se traducen en ordenamientos estatutarios. De donde se deduce la importancia de la realidad preexistente -una Comunidad con conciencia de tal- para fundamentar un auténtico ordenamiento estatutario y distinguido de otros fenómenos propiamente descentralizados o de naturaleza federal.

La conexión pueblo-territorio con la Comunidad Autónoma de esas características resulta, de este modo, coherente. Los territorios de esas Comunidades Autónomas no son, «antes que nada, divisiones del territorio nacional", como se ha afirmado de los términos municipales (21) por el Tribunal Supremo, y precisamente para una mayor eficacia de los servicios propios de los Entes locales. Las Comunidades Autónomas forman parte de la organización territorial del Estado; pero su territorio no agota su función en ser una división del territorio nacional, constituye elemento esencial del or-

(18) La cuestión resulta paladina en el caso de la disposición adicional primera.

(19) Cfr. NiETo, op. cit., loc. cit., pág. 47.

(20) Cfr. I. de OtTo, op. cit.; F. Calasso: Gli ordinamenti giuridici del Rinascimento medioevale, Milán, 1949, y, en general, M. ADA BENEDETTO: «Statuti (Diritto intermedio)», en Digesto.

(21) Sentencia del Tribunal Supremo de 5 de octubre de 1981 (Ar. 4068). 
denamiento estatutario y soporte físico de una comunidad real que puede asentarse en ella de una manera específica (22).

Hasta tal punto para el constituyente es esencial esa relación Comunidad Autónoma-territorio, que en ocasiones utiliza este término para expresar aquélla en un inequívoco uso de un tropo literario (23). El territorio, propiamente, no es el objeto último de la norma jurídica; tiene relevancia jurídica para determinar la colectividad a la que se dirige aquélla (24). De las diferentes maneras de determinar la colectividad deriva el distinto cometido del territorio, aunque coincidan o se superpongan físicamente, como pone especialmente en evidencia la diferente naturaleza jurídica de las denominadas Administración periférica del Estado y la Administración local (25).

\section{DEFINICION DEL TERRITORIO DE LA COMUNIDAD AUTONOMA}

El territorio de la Comunidad Autónoma se define por referencia al de los Municipios y/o Provincias.

Así, en el Estatuto vasco (EPV) (art. 2, 2):

«El territorio de la Comunidad Autónoma del País Vasco quedará integrado por los Territorios Históricos que coinciden con las Provincias, en sus actuales límites de Alava, Guipúzcoa y Vizcaya, así como la de Navarra, en el supuesto de que esta última decida su incorporación de acuerdo con el procedimiento establecido en la disposición transitoria cuarta de la Constitución".

En el Estatuto catalán (EC) (art. 2):

«El territorio de Cataluña como Comunidad Autónoma es el de las Comarcas comprendidas en las Provincias de Barcelona, Gerona, Lérida $y$ Tarragona en el momento de promulgarse el presente Estatuto».

En el de Galicia (EG) (art. 2, 1):

(22) La sentencia citada en la nota anterior funda su fallo en el dato geográfico de la continuidad del territorio municipal para considerar que las islas de San Simón y San Antonio pertenecen al Municipio de Redondela y no al de Vigo, habida cuenta de que están "prácticamente despobladas».

(23) En el borrador del texto constitucional de 25 de noviembre de 1977 se hablaba de territorios autónomos. En la Constitución, cfr. artículo 144, b), implícitamente pensado para Gibraltar.

(24) Para EISENMAN, en su análisis de la estructura territorial de la Administración, la misión principal del territorio es determinar o contribuir a determinar el grupo humano sobre el que se ejercerá la competencia. Cfr. L. Eisenman: Cours de Droit administratif, París, 1982, I, págs. 202-3.

(25) No es ocasión de profundizar en el tema que llevaría a la revisión de los conceptos de descentralización y autonomía. 
«El territorio de Galicia es el comprendido en las actuales Provincias de La Coruña, Lugo, Orense y Pontevedra».

En la mayoría de los Estatutos de Autonomía, trátese de Comunidades Autónomas uni o pluriprovinciales, se recoge la definición del territorio por referencia a los Municipios o las Provincias. A título ejemplar:

Estatuto de Autonomía para Andalucía (EAN) (art. 2. ${ }^{\circ}$ ):

«El territorio de Andalucía comprende el de los Municipios de las actuales Provincias de Almería, Cádiz, Córdoba, Granada, Huelva, Jaén, Málaga y Sevilla».

Estatuto de Autonomía para Asturias (art. 2. ${ }^{\circ}$ ):

«El territorio del Principado de Asturias es el de los Municipios comprendidos dentro de los límites administrativos de la Provincia de Oviedo».

En el mismo sentido, Cantabria (art. 2, 2), La Rioja (art. 2), Comunidad Valenciana (art. 3), Aragón (art. 2, 2), Extremadura (artículo 2, 1), Madrid (art. 2), Castilla-León (art. 2).

La referencia a los Municipios se completa con la de las Merindades en el caso de Navarra (art. 4). En Canarias (arts. 2 y 22, 1) y en Baleares (arts. 2 y 5), el territorio se define primariamente por las islas.

En los Estatutos de Murcia (art. 3) y Castilla-La Mancha (art. 2), el territorio de la Comunidad Autónoma se identifica con «el de la actual Provincia» o con "el comprendido en las Provincias" que se enumeran.

La referencia preferente a los Municipios o a las Provincias para definir el territorio de las Comunidades Autónomas no tiene especial significación en la mayor parte de los casos. Más aún, esa prioridad en la referencia no equivale a una prioridad funcional, y no faltan casos en que la redacción de otros artículos de los mismos Estatutos no dejan lugar a dudas sobre el carácter prioritario o, al menos, no secundario que se otorga a la Provincia. En ese sentido, Aragón constituye un paradigma (art. 2, 1): son las Provincias quienes se constituyen en Comunidad Autónoma. En la misma dirección ha de incluirse el Estatuto de Andalucía, por la regulación específica y las funciones que atribuye a las Provincias (art. 4; confróntese también Ley 3/1983, de 1 de junio, y Decreto 154/1983, de 20 de julio).

Las diferentes formas de definir el territorio tienen, a veces, una innegable intencionalidad jurídico-política. Prescindiendo de las Co- 
munidades insulares (Canarias, Baleares), por obvios imperativos geográficos, es el caso del País Vasco, Cataluña y Castilla-La Mancha:

En el Estatuto de Castilla-La Mancha, la Provincia es el elemento básico de la organización territorial («una ley de las Cortes de Castilla-La Mancha regulará la organización territorial propia de la Región sobre la base, en todo caso, del mantenimiento de la actual demarcación provincial»).

En el EPV, el protagonismo de los denominados Territorios Históricos, «que coinciden con las Provincias», es patente. La Comunidad Autónoma del País Vasco se constituye a partir del derecho ejercitado en ese sentido, al menos inicialmente, por Alava, Guipúzcoa y Vizcaya (art. 1); cada uno de los Territorios Históricos "que integran el País Vasco» cuentan con «organización e instituciones privativas de autogobierno" que se garantizan en el Estatuto (artículo 3). Un título del Estatuto -el IV- está específicamente dedicado a las instituciones de los Territorios Históricos, con unas competencias exclusivas, que se enumeran, y un régimen electoral específico para sus órganos representativos. Y la disposición transitoria tercera permite que el traspaso de servicios de enseñanza pueda realizarse directamente desde el Estado a las Diputaciones Forales y no necesariamente a la Comunidad Autónoma (26).

El caso catalán ofrece una aproximación muy diferente. La referencia a la Provincia es la constitucionalmente imprescindible (artículos 2 y 5). Se pone el acento en Comarcas y Municipios. La reluctancia respecto a las Provincias y a su órgano de representación - las Diputaciones Provinciales- se pone de manifiesto en la disposición adicional cuarta («a partir de la entrada en vigor del presente Estatuto, los presupuestos que elaboren y aprueben las Diputaciones Provinciales de Barcelona, Gerona, Lérida y Tarragona se unirán al de la Generalidad»), y resultó palmaria en la Ley de Cataluña 6/ 1980 , de 17 de diciembre, de transferencia urgente y plena de las Diputaciones catalanas a la Generalidad, declarada inconstitucional en su parte fundamental por el Tribunal Constitucional (sentencia del Tribunal Constitucional de 28 de julio de 1981). En el preámbulo de la citada Ley se proclamaba, sin embargo, que «el mantenimiento de las funciones actuales de las Diputaciones es un obstáculo para la nueva ordenación territorial catalana», que habrá

(26) Sobre las peculiaridades y problemas, cfr. ad exemplum J. L. IBARRA RoBLES y A. Zurita Laguna: "Organización Foral», en Primeras Jornadas de Estudio del Estatuto de autonomía del País Vasco, tomo III, Oñati, 1983, págs. 1297 y ss.; J. LEGUINA VILLA: «Los Territorios históricos vascos: poderes normativos y conflictos de competencias», en Escritos sobre autonomias territoriales, Madrid, 1984. 
de basarse en el fortalecimiento de la vida municipal, «la institucionalización administrativa de las Comarcas» y el establecimiento de Entidades supracomarcales «que se adapten mejor que las Provincias a las necesidades de la sociedad catalana actual». Su artículo 9, declarado inconstitucional, preveía la constitución de unos Consejos Territoriales de base comarcal para sustituir a las Diputaciones Provinciales una vez que se hubiese producido su desaparición.

En ese contexto general, el artículo 2 del EG aparece más lejos del EPV que del EC. La no referencia a los Municipios permite un pronunciamiento más adecuado a la organización territorial, que menciona el apartado 2. La Provincia cumple aquí la función de elemento de referencia extrínseco, cuyo carácter necesario proviene de su reconocimiento en la Constitución (art. 141) y cuya garantía constitucional ha sido ampliamente razonada en la citada sentencia del Tribunal Constitucional (f. 3 y 4). Pero esa necesidad no impide una revisión de su ámbito competencial, una "modificación reductora o ampliadora de la autonomía provincial inducida por la creación de las Comunidades Autónomas».

En el EG no se atribuye a la Provincia una específica funcionalidad como elemento ordenador del territorio de la Comunidad Autónoma. Y aquella ausencia de mención concreta a los Municipios en el artículo 2 permite atribuir, al nivel de ellos, un papel significativo a las Comarcas y Parroquias rurales, que aparecerán reconocidas en el propio EG como «Entidades locales propias de Galicia” (art. 27, 2).

Galicia, de otra parte, se concibe desde el comienzo del EG como una unidad. Constituye el sujeto de todo el Estatuto. La Comunidad Autónoma de Galicia no se constituye a partir de las cuatro Provincias, como en otros casos antes citados, o como se define la Provincia en el artículo 141 de la Constitución ("agrupación de Municipios y división territorial»). La delimitación del territorio de Galicia por el de las actuales Provincias de La Coruña, Lugo, Orense y Pontevedra no tiene, por ello, más significación que el de un límite externo.

Tal referencia al territorio de las actuales Provincias se relacionaba coherentemente con la disposición adicional del Proyecto de EG, suprimida durante los debates en las Cortes, según la cual

«se podrá incorporar a la Comunidad Autónoma gallega cualquier territorio limítrofe de características históricas, geográficas, económicas, cultura- 
les o lingüísticas semejantes, de acuerdo en todo caso con el artículo 141, 1, de la Constitución» ${ }^{27}$.

El supuesto no era exactamente coincidente con el que justifica el actual artículo 8 del EV, que se refiere a territorios o Municipios enclavados en su totalidad en el territorio de aquella Comunidad Autónoma (28). La alteración, por tanto, del territorio de la Comunidad Autónoma (art. 2 EG) requerirá la reforma del Estatuto (29).

De otra parte, Comunidades Autónomas, Provincias y Municipios son elementos de la división y organización del territorio del Estado (art. $137 \mathrm{CE}$ ). Existe una evidente superposición de territorios. El territorio del Estado es un continuo en el que no puede haber territorios exentos (30).

Provincias y Municipios forman parte del territorio de las Comunidades Autónomas. Pero por esta circunstancia no se convierten "en meras divisiones para el cumplimiento de los fines de la Comunidad aunque puedan cumplir esta función", ha reconocido el Tribunal Constitucional. Tienen «un carácter bifronte» y su régimen jurídico no es ni «intercomunitario» ni «extracomunitario». Por ello

«... pueden ser autorizados por el ordenamiento para asumir a título singular el desempeño de funciones o la gestión de servicios que el Estado proponga transferirles o delegarles y que se corresponden con su ámbito de intereses propios, definido por la Ley».

Aunque las competencias que el Estatuto atribuye a la Comunidad Autónoma sobre el Régimen local

(27) El término «territorio» no se circunscribe necesariamente al de Municipio, como hacía el artículo 2. del Estatuto de 1936, y permitía la incorporación del fenómeno comarcal.

(28) Menos similitud tenía el supuesto con el previsto en la disposición adicional primera del EA claramente pensado para Gibraltar («una vez que dichos territorios hayan vuelto a la soberanía española»).

(29) No parece que encaje en «simple alteración de la organización de los poderes de la Comunidad Autónoma sin afectar a las relaciones de la Comunidad Autónoma con el Estado" del artículo $57 \mathrm{EG}, \mathrm{y}$, sin embargo, puede resultar excesivamente rígido el procedimiento del artículo 56 EG.

(30) Como dice la sentencia del Tribunal Supremo de 28 de junio de 1980 (Aranzadi 3366), «todo el territorio nacional forma parte del de los Municipios por cuanto éstos integran el Estado español». Cfr. sentencia del Tribunal Supremo de 30 de junio de 1979 (Ar. 2975); sentencia del Tribunal Supremo de 8 de julio de 1983, citada, supra. La larga polémica entre el título estatal basado en la idea de dominio nacional y el local basado en la jurisdicción en el término municipal se ha resuelto en el sentido del texto, lo que se traduce en la preeminencia municipal en los supuestos de competencias concurrentes. Por ejemplo, sentencias del Tribunal Supremo de 3 de diciembre de 1982 (Ar. 7774), 19 de diciembre de 1983 (Ar. 6345) y 18 de mayo de 1984 (Ar. 2905), aunque matizadamente (Sentencia del Tribunal Supremo de 20 de febrero de 1984, Ar. 1078). La misma doctrina se aplica a las Comunidades Aut6nomas (Sentencia del Tribunal Constitucional de 3 de julio de 1984). 
«... aconsejan sin duda a dar a la Comunidad Autónoma, sobre todo cuando los receptores de la transferencia o delegación son los Municipios, algún género de intervención en el procedimiento que a ellas conducen» ${ }^{31}$.

\section{FUNCIONALIDAD DEL TERRITORIO}

\section{Delimitación de competencias}

El territorio es elemento delimitador de las competencias de la Comunidad Autónoma en relación con las demás Comunidades y con el Estado. En ello radica su funcionalidad general. Por eso los Estatutos contienen una expresa declaración respecto del límite territorial de sus competencias del siguiente tenor: "Las competencias de la Comunidad Autónoma de Galicia se entienden referidas a su territorio» (art. 37, 1, EG).

Se trata, evidentemente, de una regla general que se confirma en aquel precepto estatutario excepcional (32). Como ha declarado el Tribunal Constitucional, esa referencia territorial "responde a la necesidad de hacer compatible el ejercicio simultáneo de las competencias asumidas por las distintas Comunidades» (S. TC 44/1984, de 27 de marzo).

Aunque el Estatuto es "parte integrante» del ordenamiento jurídico del Estado (art. 147, 1, CE), ello no exime de la necesaria articulación de éste y del autonómico, que obedecerá a diferentes reglas según sea la naturaleza de las competencias -exclusivas o compartidas - de la Comunidad Autónoma. Por eso

«en materia de competencia exclusiva de la Comunidad Autónoma el Derecho propio de Galicia es aplicable en su territorio con preferencia a cualquier otro» (art. $38 \mathrm{EG}$ ),

lo que no es óbice para que el territorio juegue también en relación con competencias de desarrollo o ejecución de normas estatales (33).

(31) Sentencia del Tribunal Constitucional 84/1982, de 23 de diciembre.

(32) Salvo que el Estatuto contenga disposición expresa en contrario, las competencias se entienden referidas al ámbito territorial de la Comunidad, dice el artículo 20,6, del EPV, en el que se apoya el Tribunal Constitucional para limitar la competencia en materia de cooperativas a aquel territorio (Sentencia del Tribunal Constitucional 72/1983, de 29 de julio). La referencia que se hace en la sentencia al artícu10 10, 13, del EPV (fundaciones... en tanto desarrollen principalmente sus funciones en el País Vasco), lejos de servir de excepción, confirma la regla; porque se desarrollan actividades en el País Vasco tiene esta Comunidad Autónoma competencia sobre ellas.

(33) También juega en ese caso la garantía constitucional en favor de la competencia de las Comunidades Autónomas, como ha declarado en varias sentencias el Tri- 
Desde esta perspectiva, ha de considerarse el mar territorial y el espacio aéreo como partes integrantes del territorio de la Comunidad Autónoma (34). Para negarlo no sería, desde luego, definitivo el argumento del dominio público estatal, que descansaría en la confusión entre dominio y jurisdicción, que está en el fondo de numerosos problemas planteados por la legislación sobre dominio marítimo (35).

El EG proporciona argumentos favorables a aquella tesis. El artículo 27, 15, reconoce como competencia exclusiva de la Comunidad Autónoma «la pesca en las rías y demás aguas interiores, el marisqueo...» (36). Desde luego, esas aguas forman parte del territorio de la Comunidad Autónoma en virtud del citado artículo 37 EG (37). El mismo argumento es aplicable a la competencia reconocida en el artículo 29, 4, aunque se trate de competencias compartidas, de ejecución ("Corresponde a la Comunidad Autónoma gallega la ejecución de la legislación del Estado en las siguientes materias: ...Cuatro. Vertidos industriales y contaminantes en las aguas territoriales del Estado correspondientes al litoral gallego").

A la misma conclusión puede llegarse respecto del espacio aéreo (38). El artículo 27, 9, del EG reconoce la competencia exclusiva sobre los «aeropuertos y helipuertos no calificados de interés gene-

bunal Constitucional en torno al concepto de bases. El artículo 10, segundo párrafo, del EA contiene un precepto de gran interés para dilucidar el régimen de la preferencia en la aplicación del Derecho estatal o autonómico en el caso de competencias compartidas, es decir, en aquéllas que suponen que la Comunidad Autónoma desarrolle las normas estatales, ya que supone la prevalencia del Derecho comunitario en contra de lo que pretendía la LOAPA en su artículo 1. Merece la pena transcribirlo literalmente: "Cuando la competencia de la Comunidad Autónoma consista en el desarrollo - reglamentación de la legislación del Estado, las normas dictadas por aquélla serán de aplicación preferente a cualquier otra de igual naturaleza y rango». Cfr. J. L. VILLAR EZCURRA: "La eficacia territorial de las normas», en $R E D A, 26$ (1980), págs. 387 y ss.

(34) R. Múgica y M. A. Larburu: «El territorio», en Primeras Jornadas de Estudio del Estatuto de autonomía del País Vasco, Oñati, 1983, págs. 223-4, cuestionan tal pertenencia.

(35) Cfr. J. L. MEILÁN GIL: «Competencias administrativas en la actividad portuaria», en Jornadas Conmemorativas del I Centenario. Junta del Puerto, La Coruña, 1978, págs. 71-89. En el sentido del texto, sentencia del Tribunal Constitucional de 3 de julio de 1984.

(36) En las sucesivas redacciones del EG se ensayaron diversos términos - bajura, litoral - para definir en qué aguas la pesca constituiría materia de competencia exclusiva de la Comunidad Autónoma gallega. La expresión «aguas interiores», en algún momento de la elaboración del texto, se introdujo como equivalente a «entre puntas» de clara ascendencia internacionalista.

(37) La explicación a que llevaría la negativa es ciertamente «rebuscada». Cfr. S. MuÑoz Machado: Curso..., cit., I, pág. 195.

(38) Para Muñoz MAchado no cabe duda de que "a los efectos de las competencias limitadas de que disponen las Comunidades Autónomas, el suelo y el espacio aéreo deben considerarse parte de su territorio». Ibídem. 
ral por el Estado». Ese precepto ha de interpretarse de acuerdo con lo que dispone el artículo 149, 1, 20, de la CE, que atribuye al Estado competencias exclusivas sobre «aeropuertos de interés general; control del espacio aéreo, tránsito y transporte aéreo". Precisamente esta competencia relativa al control del espacio aéreo constituye la razón fundamental en que se apoya el Tribunal Constitucional para resolver en favor del Estado un conflicto positivo de competencias relativo a las facultades que el Real Decreto 2858/1981, de 27 de noviembre, sobre calificación de aeropuertos civiles, atribuía al Estado sobre todos los aeropuertos y no sólo los de interés general (S. TC 68/1984, de 11 de junio).

El espacio aéreo puede ser el soporte físico para la difusión y transmisión de sonidos e imágenes, sobre lo que existen competencias compartidas, ya que al Estado le corresponden las bases (artículo $149,1,27)$ y a las Comunidades Autónomas su desarrollo y ejecución. El artículo 34 del EG reconoce la correspondiente competencia de la Comunidad Autónoma sobre la materia «en los términos y casos establecidos en la ley que regule el Estatuto jurídico de la radio y la televisión». El artículo $2 .^{\circ}, 2$, de la Ley 4/1980, de 10 de enero, prevé la concesión de un tercer canal "para el ámbito. territorial de cada Comunidad Autónoma», a gestionar directamente por ella (39).

El territorio sirve directamente en ocasiones a la finalidad de definir a quién corresponde la titularidad de la competencia sobre una. materia: ferrocarriles y carreteras, aprovechamientos hidráulicos, canales y regadíos, instalaciones de producción, distribución y transporte de energía eléctrica, obras públicas (arts. 27, 8, 12, 13 y 7 del EG y art. 148, 1, 4. ${ }^{\mathrm{a}}$ y $5 .^{\mathrm{a}}, \mathrm{CE}$ ).

Para que sean competencia exclusiva de la Comunidad Autónoma. es preciso que esas actividades se desarrollen o discurran integramente en su territorio y no afecten a otra Provincia o Comunidad Autónoma (S. TC 97/1983, de 16 de noviembre) (40). Pero aunque aquélla sea una condición necesaria, no siempre lo es suficiente.

En el caso de las carreteras no han de estar «incorporadas a la

(39) Las mismas conclusiones para el subsuelo (art. 28, 3, EG, competencia de desarrollo y ejecución). Cfr. MuÑoz MaChaDo, ibídem.

(40) Esta última precisión figura expresamente en el EG referido al aprovechamiento de energía eléctrica y obras públicas.

Por su relación necesaria con el territorio no se citan en el texto las competencias sobre ordenación del territorio y del litoral y del urbanismo (art. 27, 3, EG). Cfr. A. Guarta: "Competencia de las Regiones en materia urbanística», en $R D U, 69$; F. GonzÁlez NAVARRo: Autonomías y Ley del Suelo, Madrid, 1981. 
red del Estado", o no integradas en itinerarios de interés general del Estado, como con mayor flexibilidad se opera en los Decretos de transferencias de funciones y servicios (41).

En aquel sentido se ha pronunciado el Tribunal Constitucional en un conflicto de competencia en materia de autorización de instalaciones eléctricas:

«La ubicación de la línea dentro del territorio de la Comunidad Autónoma es condición necesaria, pero no suficiente..., lo que habrá que comprobar en cada caso es si cada línea se integra o no en la Red General Peninsular, lo cual no siempre sucede con todas las líneas de alta tensión" (Sentencia del Tribunal Constitucional de 2 de febrero de 1984).

Cuando una actividad de las enumeradas no se desarrolla integramente dentro del territorio de la Comunidad Autónoma, ésta tendrá, a lo sumo, competencias de ejecución, pero no exclusivas (Sentencia TC 53/1983, de 3 de mayo).

Dada la superposición de los territorios como elementos definidores de las competencias, se comprende que no pueda establecerse una delimitación rígida que los convirtiese en compartimientos estancos, incomunicables. El propio Tribunal Constitucional ha_declarado en relación con el territorio de las Comunidades Autónomas que «dicho límite territorial ha de interpretarse con flexibilidad suficiente para no vaciar de contenido las competencias asumidas" (S. TC 44/1984, de 27 de marzo). Es muy difícil que el ejercicio de una competencia por una Comunidad Autónoma sobre una actividad que se desarrolla en su territorio no tenga incidencia alguna fuera de él. Por ello se ha podido afirmar que

«esta limitación territorial de la eficacia de las normas y actos no puede significar, en modo alguno, que le esté vedado por ello a estos órganos, en uso de sus competencias propias, adoptar decisiones que puedan producir consecuencias de hecho en otros lugares del territorio nacional. La unidad política, jurídica, económica y social de España impide su división en

(41) Artículo 27, 8, del EG y artículo $10^{\circ}$ de la Ley 6/1983, de 22 de junio, de limitaciones a la propiedad en las carreteras no estatales de Galicia.

En esa expresión encuentra su enganche legal la titularidad estatal de la Autopista del Atlántico, que discurre íntegramente por territorio de la Comunidad Autónoma gallega.

En el Real Decreto 3317/1982, de 24 de julio, sobre traspaso de funciones y servicios a la Comunidad Autónoma de Galicia en materia de carreteras, el criterio que se utiliza es el de itinerario de interés general del Estado, para calificar a las carreteras del Estado, frente a los itinerarios autonómicos que tienen un carácter residual respecto de aquél. Se adopta, por tanto, y acertadamente, un criterio más flexible que el físico de red, sin que ello suponga olvidar que todas las carreteras constituyen un sistema independientemente de la titularidad de la competencia administrativa. Cfr. J. L. MeILÁN GiL: El territorio, protagonista del desarrollo, Madrid, 1971. 
compartimientos estancos y, en consecuencia, la privación de las Comunidades Autónomas de la posibilidad de actuar cuando sus actos pudieran originar consecuencias más allá de sus límites territoriales equivaldría necesariamente a privarlas, pura y simplemente, de toda capacidad de actuación» (Sentencia del Tribunal Constitucional de 16 de noviembre de 1981) ${ }^{42}$.

Habrá, por tanto, que indagar en cada caso la naturaleza jurídica de la actividad y su vocación comunitaria o supracomunitaria para dilucidar si la competencia corresponde a la Comunidad Autónoma $o$ al Estado. $Y$ en ese sentido el Tribunal Constitucional, a propósito de cooperativas, ha tenido oportunidad de distinguir uno. y otro supuesto.

Así, corresponden las competencias a la Comunidad Autónoma. cuando las relaciones jurídicas que las cooperativas establezcan con terceros fuera del territorio «tengan carácter instrumental» (Sentencia TC 44/1984, de 27 de marzo).

Tratándose de cooperativas de crédito, las actividades realizadas. fuera del territorio de la Comunidad corresponden a la misma naturaleza — «la actividad típica»— de aquellos Entes:

«No se trata, pues, de simples consecuencias de hecho derivadas de la actividad cooperativa que se realiza dentro del País Vasco, ni de relaciones jurídicas o actividades con terceros de carácter instrumental, sino que la dimensión extraterritorial forma parte esencial de la configuración de la entidad cooperativa».

Por ello se concluye sentando la doctrina que «la competencia atribuida a la Comunidad Autónoma abarca las cooperativas de ámbito provincial intracomunitario y las de ámbito supraprovincial pero no supracomunitario" (en la misma dirección la S. TC 48/1982, de 12 de julio).

A conclusión equivalente llega el Tribunal Constitucional en materia de transportes terrestres. Entre los distintos argumentos manejados, el definitivo es el del ámbito territorial del servicio. Siendo nacional la competencia ha de corresponder al Estado:

«a un servicio concebido como de ámbito nacional la reglamentación ha de proceder de una instancia unitaria, que ha de ser, cabalmente, la que tenga competencia sobre el ámbito territorial al que se extiende el servicio».

(42) La sentencia del Tribunal Constitucional 72/1983 declar6 inconstitucional la disposición final de la Ley vasca $1 / 1982$ sobre cooperativas que establecía: «La presente Ley se aplicará a todas las cooperativas con domicilio en la Comunidad Autónoma del País Vasco, con independencia de su ámbito territorial de actuación", estimando que vulnera el artículo 20,6 , del EPV y el 49,3 , de la CE. 
El territorio, obviamente, sirve también para la delimitación de las competencias del Estado. Y así el artículo 154 de la Constitución prevé la existencia de un Delegado del Gobierno que «dirigirá la Administración del Estado en el territorio de la Comunidad Autónoma y la coordinará, cuando proceda, con la Administración propia de la Comunidad» (43).

\section{La ORGANIZACIÓN JUDICIAL}

También el territorio constituye un elemento de la organización judicial. En ese sentido, un Tribunal Superior de Justicia culmina la organización judicial «en el ámbito territorial de la Comunidad Autónoma» (art. 152, CE), lo que para Galicia concreta el artículo 21 del EG, dentro de su capítulo III, que lleva el' expresivo epígrafe «De la Administración de Justicia en Galicia». En el proyecto de EG su artículo $9 .^{\circ}$ recogía equívocamente a los Tribunales de Justicia, junto al Parlamento, Xunta y su Presidente, como instituciones a través de las cuales se ejercían «los poderes de la nacionalidad gallega».

El Tribunal Constitucional ha tenido ocasión de precisarlo con motivo de un recurso de inconstitucionalidad promovido por el Parlamento vasco:

"Las competencias de los órganos jurisdiccionales no son competencias de la Comunidad Autónoma, que se correspondan con la esfera de sus intereses propios... La relación con la Comunidad Autónoma no es una relación orgánica, sino una relación territorial que deriva del lugar de su sede» (Sentencia del Tribunal Constitucional de 14 de julio de 1981).

El territorio de la Comunidad Autónoma puede considerarse incluido en el "propio ámbito de autonomía», que debe ser afectado por una ley o acto legislativo del Estado a fin de que se reconozca la legitimación para interponer un recurso de inconstitucionalidad. El Tribunal Constitucional lo ha negado, sin embargo, en un caso concreto, ya que aquella expresión «no puede reducirse a un criterio meramente cuantitativo" cuando se refiere a leyes cuyo ámbito se extiende a todo el Estado (S. TC 14 julio 1981). El voto particular, no obstante, reconoce que aun tratándose de competencia exclusiva del Estado, su ejercicio puede afectar a la gestión de los intereses de las Comunidades Autónomas, que comprendían «no sólo los ju-

(43) Desarrollado por Ley $17 / 1983$, de 16 de noviembre. Cfr. artículo $1 .^{\circ}$ y artículo $4 .^{\circ}$ relativo a la sede que modifico el artículo 4 del Real Decreto 2238/1980, de 10 de octubre, que expresamente deroga la Ley. 
rídico-administrativos» (competencia de sentido estricto), sino «los intereses políticos consagrados en la Constitución y en sus respectivos Estatutos", y por ello no le resultaría indiferente que la jurisdicción —exclusiva del Estado- no se agote en órganos estatales con sede en la Comunidad Autónoma (44).

El territorio afecta a la determinación del órgano judicial competente para entender en actos delictivos cometidos por miembros del Parlamento gallego durante su mandato: Tribunal Superior de Galicia o Sala de lo Penal del Tribunal Supremo si se realizaron en el territorio de Galicia o fuera de él (art. 11, 3, EG).

\section{DERECH OS INDIVIDUALES}

El sistema electoral se relaciona también con el territorio. El artículo 11, 2, del EG, además de configurarlo como de representación proporcional, prescribe se asegure «la representación de las diversas zonas del territorio gallego" repitiendo el mandato constitucional (art. $152 \mathrm{CE}$ ).

Por último, el territorio cumple la finalidad general de atribuir la "condición política de gallegos» (art. 3., 1, del EG), una expresión un tanto grandilocuente y convencional con la que se quiere aludir a los derechos políticos de los ciudadanos, en especial los del ejercicio de los derechos electorales activos y pasivos. En realidad, el territorio de Galicia sirve para la función de fijar la «vecindad administrativa», bien lejos de la condición de galleguidad civil ligada al ius sanguinis, que aparece tímidamente en el artículo $3 .^{\circ}, 2$, del EG y absolutamente irrelevante para la configuración de una galleguidad política (45).

Cuando el artículo $4 .^{\circ}, 1$, del EG se refiere a los gallegos está utilizando una expresión sincopada de lo que establece el citado artículo $3 .^{\circ}, 1$, del EG. Por eso resulta coherente que los derechos, libertades y deberes fundamentales de aquéllos «son los establecidos en la Constitución». Y, en consecuencia, el territorio no puede constituir un elemento de discriminación, en contra del principio de igualdad reconocido por el artículo 14 de la CE (así S. TS 9 de febrero de 1984, Ar. 790) (46).

(44) La sentencia del Tribunal Constitucional 84/1982 acepta ese criterio minoritario para admitir la legitimación de la Comunidad Autónoma.

(45) Sobre los problemas de la relación entre vecindad civil y administrativa en relación con el artículo 7,2, del EC y los antecedentes históricos de ésta, vid. M. CocA PAYERA: "Vecindad civil y vecindad administrativa. Génesis de un concepto legal», en Revista Jurídica de Cataluña, I (1981).

(46) El Tribunal Supremo declaró la nulidad de las Ordenes ministeriales de 17 
Como principio rector de la política social y económica de los poderes públicos de la Comunidad, en claro paralelismo con el capítulo III del Título I de la Constitución, el artículo $4 .^{\circ}, 3$, del EG recoge «el derecho de los gallegos a vivir y trabajar en su propia tierra». El alcance de la expresión rebasa el de un pío deseo y no llega al de un auténtico derecho subjetivo alegable directamente en los Tribunales, pero han de informar la legislación de la Comunidad Autónoma, interpretando el Estatuto a la luz del artículo 53, 3, de la Constitución (47).

\section{LA ORDENACIÓN DE LAS AdMINISTRACIONES PÚBLICAS}

El territorio ha de desempeñar una decisiva función de protagonismo en la nueva ordenación de las Administraciones públicas, que inexorablemente ha de derivarse de la existencia de Comunidades Autónomas. No es éste el momento de desarrollar la tesis. Baste, simplemente, apuntar las líneas en que esa ordenación debería formularse.

En primer lugar, la influencia concreta del territorio se ha de dejar sentir, sobre todo en algunos casos (País Vasco, Cataluña, Navarra, Canarias, Galicia), en lo que en algunos Estatutos se denomina «organización territorial». Es netamente una obviedad que conviene, sin embargo, recordar. En determinados supuestos esa organización territorial adquiere el carácter de "propia» de la Comunidad Autónoma, ligada al concepto de competencias exclusivas de la misma. Así se pone de manifiesto en el Estatuto gallego mediante la interpretación sistemática del artículo 2, 2 («la organización territorial de Galicia tendrá en cuenta la distribución de la población gallega y sus formas tradicionales de convivencia y asentamiento"), y el artículo 27, 2, que reconoce como competencia exclusiva de la Comunidad Autónoma «la organización y régimen jurídico de las Comarcas y Parroquias rurales como Entidades locales propias de Galicia».

La introducción del ámbito comunitario obliga a una redistribución de funciones correspondientes a los ámbitos provincial y municipal preexistentes, mediante técnicas de delegación, de atribución

de diciembre de 1982 y 11 de enero de 1983, que condicionaban el destino en plazas docentes de las Comunidades Autónomas al número de los funcionarios que, procedentes de ellas, saliesen destinados fuera de su territorio.

(47) La identificación de territorio con «tierra propia» revela la concepción que subyacía en los redactores del Estatuto sobre la galleguidad $-y$ del territorio como un elemento al servicio de la misma - más allá del concepto de vecindad administrativa como título para el nacimiento de nuevos derechos políticos. 
o asunción por vía legislativa, o a utilizar las de programación y coordinación precisamente en función de la incidencia en el territorio.

Más aún, tal redistribución ha de hacerse teniendo en cuenta la propia estructura deseada de la Administración autonómica, como consecuencia de la efectiva asunción de competencias anteriormente de la Administración del Estado. Un error fácilmente apreciable en la organización de la mayoría de las Comunidades Autónomas es la reproducción en buena medida de la división orgánica de la Administración centralizada. La existencia de Comunidades Autónomas, al partir de cero, podría servir para superar disfunciones que tienen un fundamento puramente histórico y en absoluto racional. La nueva perspectiva para la distribución de funciones $\mathrm{y}$, consiguientemente -no antecedentemente, como por desgracia se ha hecho desde los regímenes preautonómicos-, es precisamente el territorio como elemento unificador. Las competencias estatales al ser asumidas por la Comunidad Autónoma deben sufrir cierto proceso de refracción por incidir en su territorio (48).

La redistribución de competencias intracomunitarias y sus consecuencias de reordenación de las estructuras orgánicas influirá lógicamente en la concepción misma del poder autonómico, de su titularidad y ejercicio, dando lugar a modelos centralizados o descentralizados.

Por último, el propio ordenamiento jurídico estatal existente, aun antes de su renovación como consecuencia del ejercicio de las competencias estatutariamente atribuidas a la Comunidad Autónoma, ha de ser reinterpretado a la luz de las bases de la organización territorial propia de aquélla. Un supuesto paradigmático es el que se refiere al asentamiento de la población, y en concreto el concepto de "núcleo de población» a efectos de la legislación del suelo, de aperturas de farmacias, de actividades clasificadas, etc.

En tanto no se produzca la correspondiente legislación autonómica, aunque se trate de desarrollo, los preceptos vigentes deberán ser aplicados de acuerdo con la interpretación que se deduce de los Estatutos ya en vigor. Se eliminarían sin notorias injusticias, al menos, retrasos en la obtención de la solución justa, que se producen, a veces, por una interpretación unilateral de una legislación estatal uniformadora, en la que las peculiaridades territoriales tienden a ser contempladas como cuestiones residuales y accesorias.

(48) Cfr., en general, J. L. MEILÁN GIL: El territorio..., cit. 